\title{
A Single Stage Boost Inverter for Secondary Power Conversion Stage-Less PV Systems
}

\author{
Mr. Avinash $\mathbf{R}^{1}$, Mr. Savyasachi G K ${ }^{2}$, Mr. Raghunath M J ${ }^{3}$, Mr. Pruthviraj B G ${ }^{4}$ \\ Assistant Professor, Dept of Electrical and Electronics Engineering, VVCE, Mysuru, India ${ }^{1,2,3}$ \\ Assistant Professor, Dept of Electrical and Electronics Engineering, SVCE, Vidyanagar, Bengaluru, India ${ }^{4}$
}

\begin{abstract}
This paper describes a new voltage source inverter (VSI) referred to as a BOOST INVERTER or boost DCAC converter. The main attribute of the new inverter topology is the fact that it generates an ac output voltage larger than the dc input one, depending on the instantaneous duty cycle. This property is not found in the classical VSI, which produces an ac output instantaneous voltage always lower than the dc input one. For the purpose of optimizing the boost inverter dynamics, while ensuring correct operation in any working condition, a sliding mode controller is proposed. This new inverter is intended to be used in uninterruptible power supply (UPS) and ac driver systems design whenever an ac voltage larger than the dc link voltage is needed, with no need of a second power conversion stage (SPCS). This boost inverter topology generates an AC voltage which is larger than that of the input DC voltage in a single stage conversion.
\end{abstract}

Keywords: Voltage Source Inverter (VSI), Boost Inverter, Uninterruptible Power Supply (UPS), DC voltage.

\section{INTRODUCTION}

An inverter is an electronic device or circuitry that changes direct current (DC) to alternating current (AC). The input voltage, output voltage and frequency, and overall power handling, are dependent on the design of the specific device or circuitry.A power inverter can be entirely electronic or may be a combination of mechanical effects (such as a rotary apparatus) and electronic circuitry. Static inverters do not use moving parts in the conversion process.

\section{APPLICATIONS}

Typical applications for power inverters include:

1) Portable consumer devices that allow the user to connect a battery, or set of batteries, to the device to produce AC power to run various electrical items such as lights, televisions, kitchen appliances, and power tools.

2) Use in power generation systems such as electric utility companies or solar generating systems to convert DC power to AC power.

3) Use within any larger electronic system where engineering need exists for deriving an AC source from a DC source.

\section{VOLTAGE SOURCE INVERTERS}

The conventional voltage source inverter (VSI) shown in fig a, referred to as a buck inverter, is probably the most important power converter topology. It is used in many distinct industrial and commercial applications. Among these applications, uninterruptible power supply (UPS) and ac motor drives are the most important. One of the characteristics of the buck inverter is that the instantaneous average output voltage is always lower that the input de voltage.

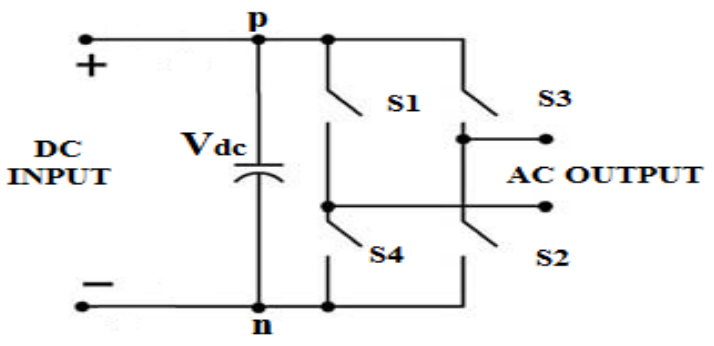

Fig a

As a consequence, when an output voltage larger than the input one is needed, the following alternative topologies or methods are used.

- Using a boost dc-dc converter in between the DC source and the VSI.

- Using a current source inverter

a) USING BOOST DC-DC CONVERTER.

The below block diagram shows the arrangement of the system when Boost DC-DC converter is used.

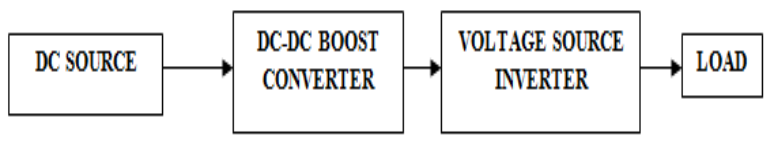

In the above method the input DC voltage is stepped up to a higher DC voltage and then fed to the VSI so that the AC voltage output will be at least $60-80 \%$ of the input DC voltage. Even though this method solves the problem to an extent, it has disadvantages also. They are

- Additional control circuit for the boost DC-DC converter 
- Additional cost and Increase in space occupancy by the converters

- And more over the AC output will not be greater than that of input DC.

\section{b) CURRENT SOURCE INVERTERS}

In this method we replace the VSI with a CSI, because practically speaking CSI's operate as boost converters and produce an AC output voltage greater than that of the input DC voltage.

But even this method has disadvantages such as

- They suffer from poor waveform quality.

- These inverters require an extra Gate turn off device with reverse voltage blocking capability.

- The important one is the design will be more complicated as we have to provide a proper return path for the input inductor. If failed it would damage the whole system.

In order to overcome all these drawbacks we need to design a inverter topology such that the stepped up DC$\mathrm{AC}$ conversion takes place in a single stage conversion, which could reduce the cost of the converter.

The conventional voltage source inverter (VSI) referred to as a buck inverter, is probably the most important power converter topology. It is used in many distinct industrial and commercial applications. Among these applications, uninterruptible power supply (UPS) and ac motor drives are the most important.

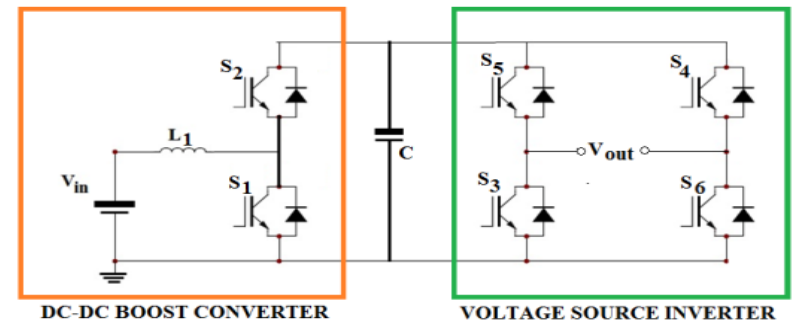

Figure b: Circuit used to generate an ac voltage larger than the dc input voltage.

One of the characteristics of the buck inverter is that the instantaneous average output voltage is always lower that the input dc voltage. As a consequence, when an output voltage larger than the input one is needed, a boost $\mathrm{dc}-\mathrm{dc}$ converter must be used between the dc source and inverter as shown in fig. 4.a Depending on the power and voltage levels involved, this solution can result in high volume, weight, cost, and reduced efficiency.

\section{BOOST INVERTER}

A Boost inverter achieves dc-ac conversion, as indicated in the below circuit diagram, by connecting the load differentially across two dc-dc converters and modulating the dc-dc converter output voltages sinusoidally. The blocks $\mathrm{A}$ and $\mathrm{B}$ represent $\mathrm{dc}-\mathrm{dc}$ converters and each converter is a current bidirectional boost converter. These
Converters produce a dc-biased sine wave output, so that each source only produces a unipolar voltage. The modulation of each converter is $180^{\circ}$ out of phase with the other, which maximizes the voltage excursion across the load. The load is connected differentially across the converters. Thus, whereas a dc bias appears at each end of the load, with respect to ground, the differential dc voltage across the load is zero.

The generating bipolar voltage at output is solved by a push-pull arrangement. Thus, the dc-dc converters need to be current bidirectional. By using the averaging concept, we obtain the voltage relationship for the continuous conduction mode given by

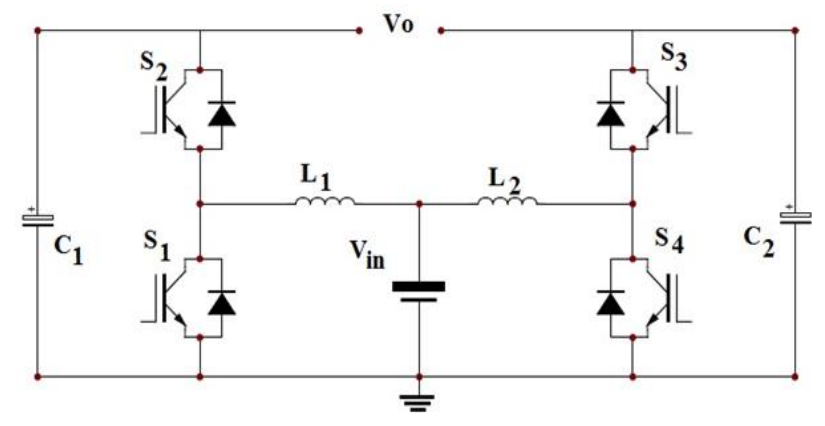

$$
\begin{gathered}
\mathrm{V}_{\mathrm{A}}=\frac{\mathrm{V}_{\mathrm{IN}}}{1-\mathrm{D}} \\
\frac{\mathrm{V}_{\mathrm{B}}=\mathrm{V}_{\mathrm{IN}}}{\mathrm{D}} \\
\mathrm{V}_{\mathrm{O}}=\mathrm{V}_{\mathrm{A}}-\mathrm{V}_{\mathrm{B}} \\
\mathrm{V}_{\mathrm{O}}=\frac{\mathrm{V}_{\mathrm{IN}}}{1-\mathrm{D}}-\frac{\mathrm{V}_{\mathrm{IN}}}{\mathrm{D}}
\end{gathered}
$$

\section{OPERATION}

The operation of the inverter can be explained by considering one converter $\mathrm{A}$ only as shown in figure 4.c.Now there are two modes of operation.

\section{Mode 1:}

For the condition, switch $S_{1}$ is closed and $S_{2}$ is open as shown in figure 4.c.1, the inductor current $\mathrm{iL}_{1}$ raises quite linearly, diode $\mathrm{D}_{2}$ is reversed biased, capacitor $\mathrm{C}_{1}$ supplies energy to the load, and Voltage $V_{1}$ decreases.

\section{Mode 2:}

For the condition, switch $S_{1}$ is open and $S_{2}$ is closed, as shown in figure 4.c.2, the inductor current $\mathrm{iL}_{1}$ flows through capacitor $\mathrm{C}_{1}$ and load. The current $\mathrm{iL}_{1}$ decreases while capacitor $C_{1}$ is recharged.

The DC gain characteristic of the boost inverter is shown in Fig.4.d. It is interesting to note that the feature of zero output voltage is obtained for $\mathrm{D}=0.5$. If the duty cycle is varied around this point, then there will be an ac voltage at the output terminal. 
Vol. 4, Issue 1, January 2017

\section{BOOST INVERTER WITH CLOSED LOOP CONFIGURATION}

The simulation was carried on MATLAB R2013 (8.1.0.604) and MATLAB SIMULINK platform software for both open loop and closed loop model.

Simulink is a block diagram environment for multidomain simulation and Model-Based Design. It supports systemlevel design, simulation, automatic code generation, and continuous test and verification of embedded systems. Simulink provides a graphical editor, customizable block libraries, and solvers for modeling and simulating dynamic systems. It is integrated with MATLAB ${ }^{\circledR}$, enabling you to incorporate MATLAB algorithms into models and export simulation results to MATLAB for further analysis. Simulink is a graphical extension to MATLAB for the modeling and simulation of systems. In Simulink, systems are drawn on screen as block diagrams. Many elements of block diagrams are available (such as transfer functions, summing junctions, etc.), as well as virtual input devices (such as function generators) and output devices (such as oscilloscopes).

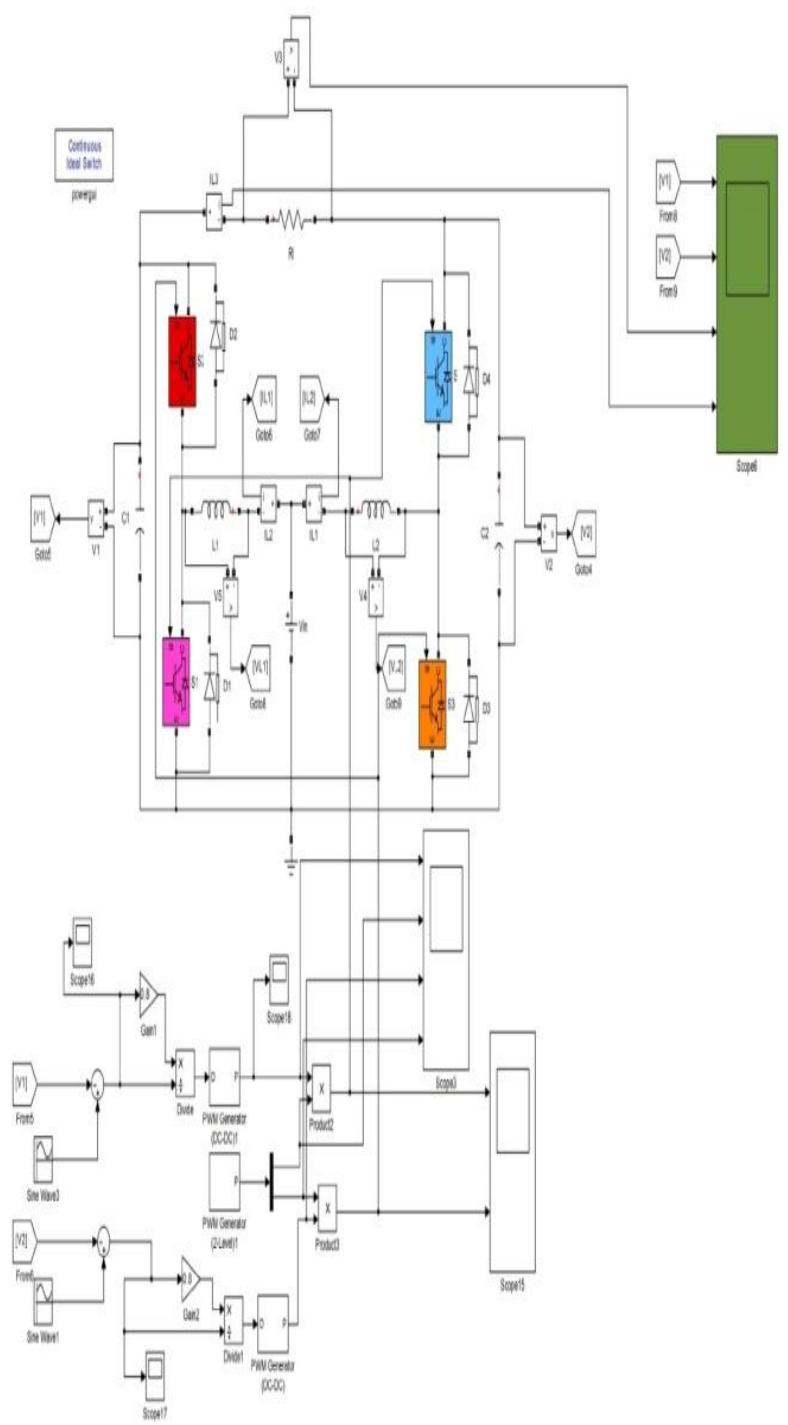

Fig 5.d Closed loop simulink model of a boost inverter
Simulink is integrated with MATLAB and data can be easily transferred between the programs. For closed loop configuration of the boost inverter a reference voltage of 300 Volts for Converter A and A reference Voltage of 150 Volts was considered and the closed loop setup was made such that the AC output voltage expected would be 150 Volts (rms) for an input of 100V DC.

As seen in the open loop simulation results it was seen that there were lot of ripples in the output waveform which would affect the quality of power so in the Closed loop design some changes were made in the inductor and Capacitor values such that there would be reduced ripple content in the waveform.

- $\mathrm{V}_{\text {in }}=100 \mathrm{~V}$

- $\mathrm{L}_{1}=\mathrm{L}_{2}=1000 \mu \mathrm{H}$

- $\mathrm{C}_{1}=\mathrm{C}_{2}=200 \mu \mathrm{F}$

Fig 5.d shows the closed loop simulink model of a boost inverter and as per the theoretical equations the output should be

$$
\mathrm{V}_{\mathrm{O}=} \mathrm{V}_{\mathrm{A}}-\mathrm{V}_{\mathrm{B}}
$$

The error signals are given by

$$
\mathrm{E}_{\mathrm{A}}=\mathrm{V}_{\text {ref }}-\mathrm{V}_{\mathrm{A}} \text { and } \mathrm{E}_{\mathrm{B}=} \mathrm{V}_{\text {ref }}-\mathrm{V}_{\mathrm{B}}
$$

\section{OUTPUT WAVEFORMS}

It is evident from the waveforms of the fig $\mathrm{c}$ that the output voltage is 115 Volts (rms) but the expected output is 150 Volts, this is because there is a decrease in voltage ripple content which in turn improves the quality of the output power. The load current is 2.25 amps.
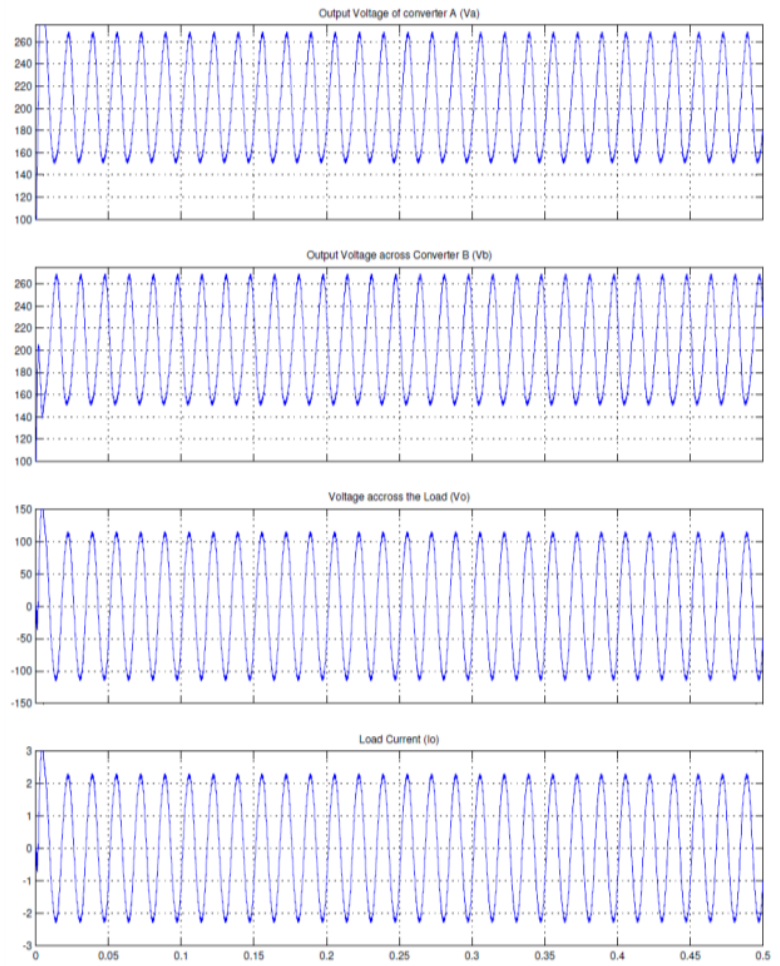

Fig. c Output waveforms, Va, Vb, Vo, Io 
Vol. 4, Issue 1, January 2017

\section{HARDWARE DESIGN}

\section{DESIGN SPECIFICATIONS:}

$\begin{array}{ll}\text { Input } & : 8 \mathrm{~V}(\mathrm{DC}) \\ \text { Output } & : 15 \mathrm{~V}(\mathrm{AC}) \\ \text { Load } & : 30 \Omega \text { resistor } \\ \text { Switching frequency } \quad: 40 \mathrm{KHz} \\ \mathrm{L}_{1}=\mathrm{L}_{2=} 50 \mu \mathrm{H} \text { and } \quad \mathrm{C}_{1}=\mathrm{C}_{2}=220 \mu \mathrm{F} / 50 \mathrm{~V} \\ \text { And the other components selected were }\end{array}$

- Diode (MUR860) : 4 Nos.

- Power Mosfet(IRF540): 4 Nos.

- Pic- $\mu$ C (PIC16F877A) : 2 Nos

\section{IMPLEMENTATION OF HARDWARE CIRCUIT}

The below figure shows the rigged up boost inverter circuit model

After purchasing all the components the hardware circuit of the designed Boost inverter was built up and the setup is as shown in the figure 6.a.The switching pulses were generated using PIC $\mu \mathrm{Cs}$ (PIC16F877A). The PIC microcontrollers were programmed to generate PWM signals with $75 \%$ and $25 \%$ duty cycles and these pulses were fed to all the four switches with specific interval of time. The switching pulses can be seen in the above figure, in order to have $180^{\circ}$ out of phase modulation between the converters the PIC- $\mu \mathrm{Cs}$ are programmed such that the switching pulses for converter B will be sent after a delay of $10 \mathrm{~ms}$

\section{RESULTS}

The output across the output terminals is $\mathbf{1 5 V}$ (rms). As shown in the figure below, the output waveform is not a pure sine wave. Here it has to be noted that the capacitor values are selected above the minimum value so as to reduce the ripples in the waveform and to get the clean output voltage as much as possible.

\section{CONCLUSION}

In this project a single phase boost inverter model is explained in detail and the simulation is done in Matlab Simulink software also a model has been designed to explain the working principle of the inverter.

From the project survey it is evident that this boost inverter topology is very effective because it has many advantages like

- Reduced cost

- Reduced size of the conversion system

- Single stage step-up of voltage is possible

But the overall efficiency will be same as that of normal two stage conversion PV systems and this inverter is suitable for applications where the output AC voltage needs to be larger than the DC input and this can offer economic and technical advantages over the conventional VSI.

\section{FUTURE SCOPE}

The boost inverter topology can be extended even to obtain three phase AC voltages. Also if advanced filter techniques are designed using computational intelligence methods the output power will be of good quality and also the efficiency will be boosted up.

Instead of using a Microcontroller, if DSP techniques are used to generate PWM signals the output will be much more accurate.

\section{REFERENCES}

[1] "DC-DC Boost Converter with Constant Output Voltage for Grid Connected Photovoltaic Application System"by Pui-Weng Chan, Syafrudin Masri, Universiti Sains Malaysia.

[2] "Closed Loop Controlled Boost Converter for Solar Installation"by Athimulam Kalirasu, Subharensu Sekar dash, Serbian journal of electrical engineering vol. 7, no. 1, may 2010, 121-130

[3] "Optimum Design for Multilevel Boost Converter" by Mostafa Mousa, IEEE student member, Mohamed Hilmy1, IEEE student member, Mahrous Ahmed, IEEE Member, Mohamed Orabi1, IEEE Senior Member, and Ahmed Alaa El-koussi,APEARC, South Valley University, Aswan City, Egypt,Cairo University, Cairo, Egypt.

[4] "Investigation of Standalone Current Source Inverter for Photovoltaic System" by Mahendra Lalwani, Prof. D. P. Kothari, Prof. Mool Singh,Dept.. of EEE, Malaviya National Institute of Technology, Jaipur.

[5] "New Trends in Hybrid Systems with Battery Inverter" by PierreOlivier MOIX STUDER INNOTEC, Rue des Casernes. 